\title{
Herbs Used for Fertility of Male Animals: A Review
}

\author{
Dibyajyoti Talukdar ${ }^{1 *}$, Athokapm Donin Luwang ${ }^{1}$ and Papori Talukdar ${ }^{2}$
}

${ }^{1}$ College of Veterinary Sciences \& A.H., Central Agricultural University, Aizawl, Mizoram, India

${ }^{2}$ College of Veterinary Science, Assam Agricultural University, Khanapara, Assam, India

*Corresponding author: dibya26@gmail.com (ORCID ID: 0000-0003-4573-8677)

\begin{abstract}
Fertility of male animals is influenced by various factors such as neurohormonal imbalances, reproductive organ tissue changes, seminal attributes, libido and sexual behavior. The global decline in male reproductive health is a big worry, and modern therapeutic options to prevent male infertility are costly, less accessible, require long-term treatment, and have a variety of adverse effects. Herbal remedies, on the other hand, are better suited to providing more comprehensive approaches to improve the male reproductive health. There is a particular set of herbs known as vajikarana or aphrodisiacs in Ayurvedic pharmacology that nourishes and stimulates the sexual tissues. This review focuses on the Ayurvedic approach to improving male reproductive health, referring to some of the most important scientifically tested herbs that have been found to boost male fertility by having stimulating or nourishing effects on the male reproductive organs.
\end{abstract}

\section{HIGHLIGHTS}

(0 Fertility of male animals is influenced by various factors such as neurohormonal imbalances, reproductive organ tissue changes, seminal attributes, libido and sexual behavior.

( Herbal remedies are better suited to providing more comprehensive approaches to improve the male reproductive health.

Keywords: Herbs, male fertility

Fertility of male animals is influenced by various factors such as neurohormonal imbalances, reproductive organ tissue changes, seminal attributes, libido, sexual behavior, environment, genotype which may result flawed spermatogenesis (Toshimori et al. 2004). It is usually said that male is the half the herd. Inspite of recognizing the role of males in improving the breed, male infertility has received lesser attention. Large scale adoption of A.I. has permitted extensive utilization of bulls and some bulls are known to have sired 100,000 to 200,000 cows in their lifetime. The spermatogenesis is a highly complex synchronized process in which the male germ cells i.e. spermatozoa are formed from the precursor diploid cells, leading to ultimate development of normal, viable haploid cells i.e. spermatozoa. The significance of spermatozoa lies in the production of maximum number of normal, viable and fertile spermatozoa. Factors that hamper the spermatogenesis process are divided into several categories namely: (1) Foetal determinants of spermatogenesis at maturity (i.e. decreased sertoli cell, germ cell expansion, Testicular germ cell cancer and testicular dysgenesis syndrome), (2) Managemental and environmental stimuli (i.e. rough handling, malnutrition, scrotal temperature, obesity), (3) Occupational exposures of environmental pollutants, chemicals (Sharpe 2010). In recent era of medical therapy, various drugs are available to treat the infertility cases; however, researchers are giving more emphasis

How to cite this article: Talukdar, D., Luwang, A.D. and Talukdar, P. 2021. Herbs Used for Fertility of Male Animals: A Review. Int. J. Ag. Env. Biotech., 14(04): 615-626.

Source of Support: None; Conflict of Interest: None 
on traditional medicine which having less adverse effects and toxicity (Austin 1991). In this article, we the authors try to review the available literature on herbal medicines and their potential roles in enhancement of spermatogenesis. Here, we focus on the scientifically tested herbs that have been established to improve male fertility.

\section{Herbs and their role in spermatogenesis}

The initiation or inhibition of neuro-chemicals, inflection of the neuroendocrine axis and their cross communications, as well as neighboring mediators working within the reproductive organs and tissues assist to bring back and manage the male reproductive processes (Sengupta, 2014; Sengupta et al. 2015). Herbs can improve the receptivity of male reproductive tissues by acting on the central or peripheral nerve systems. An orchestra of neurochemicals/neurotransmitters mediates neuronal control over male reproductive organs, with serotonin and dopamine being the primary controllers of sexual behavior, with serotonin mediating inhibitory activities and the excitatory effect of dopamine (Argiolas and Melis 2013). The ability of herbal remedies to modulate nitric oxide levels supports their use in the treatment of erectile dysfunction. The endogenous mediator of penile erection is nitric oxide (NO) (Achike and Kwan 2003). NO synthase is mostly found in brain areas involved in sexual activity, where it is synthesised (olfactory bulb, amygdala, septal structures, supraoptic and paraventricular nuclei, etc.) (Anderson 1993; Chaudhuri et al. 2014). NO is a recognised vasodilator that can enhance blood flow to the penis, generating penile erection, as well as to other male reproductive organs, allowing for greater hormonal accessibility and promoting strong reproductive function (Nehra et al., 2001). Most of the herbs interfere the HPG axis in the directive of sex hormones, like testosterone, LH, $\mathrm{FSH}$, and interstitial hormones, to synchronies the male reproductive functions such as male sexual organ development, emphasize pubertal changes, and increase overall male fertility (Dohle et al. 2003). Plant having antioxidants namely vitamin $C$, vitamin $\mathrm{E}$, carotenes, phenolic acids, phytate and phytoestrogens have been documented as reduction capacity of disease risk by scavenging the free radical present inside the body. Scientist advocates that two-thirds of the herbs present in the world have medicinal value and many of them have great antioxidant potential (Duduku et al. 2011).

\section{Herbs used for improvement of male fertility}

\section{Alpinia galanga}

Alpinia galanga plant belongs to the family of Zingiberaceae (Fig. 1, C). It is a perennial herb with rhizomatous root stocks which found in India, China, Indonesia, Japan, Malaysia and Thailand. The rhizomes and roots are used as spasmolytic, antiphlogistic and antibacterial agent (Mayachiew and Devahastin 2008). Alpinia galanga is rich in phenolic compounds namely flavonoids and phenolic acids. It also rich in alcoholic extract such as cineole, methyl cinnamate, myrecene and contains various flavones such as galangin, alpinin, kampferide and 3-dioxy-4-methoxy (Ghasemzadeh et al. 2010). The phyto-chemical present in Alpinia galanga has antioxidant and anticancer property (Kaushik et al. 2011). Antioxidants guard DNA and protects molecules from oxidative damage and can enhance semen quality and thus augment the fertility rate (Khaki et al. 2009). The plant extract had a direct affect on the testes that help to amplify the number of spermatozoa and the increased the level of testosterone production (Mazaheri et al. 2014).

\section{Apium graveolens}

Apium graveolens (Celery) belongs to the parsley (Umbelliferae) species from the Apiaceae family (Fig. 1, B). The height of the plant is $100 \mathrm{~cm}$, and it has a strong scent and fleshy with solid stems (Khare 2007). It was reported that the celery contains phytoestrogens, which having direct effect on fertility (Kooti et al. 2014). Previous studies reported that celery can safe testes from functional and structural damages and sperm from toxicity caused by atrazine (Abarikwu et al., 2012) and quinine sulfate (Farombi et al. 2012), protects the testes against sodium valproate (Hamza and Amin 2007) and di (2-ethylhexyl) phthalate (Madkour 2014). In a study of Kooti et al. (2014) revealed that celery significantly increased in the number of sperms, sertoli cells, and primary spermatocyte compared to the control group while they administered 200 and $300 \mathrm{mg} / \mathrm{kg}$ of celery to the rats for 60 days. They also reported that celery increased spermatogenesis 
in male rats, without any destructive effects on testicular tissue.

\section{Aloe barbadensis miller (Aloe vera)}

Aloe vera is a perennial herbaceous plant which looks like cactus (Fig. 1, D). This plant easily grows in a dry temperate area, which is found in Asia, Africa, North America and Europe. Aloe vera is used to treat the various ailments of human. Aloe vera extract having antioxidant property which acts circuitously by intensification of vitamin C and E (Modaresi and Khodadadi 2014). The Aloe vera also used orally, as a laxative during anal fissures, hemorrhoids and anorectal surgery in gastrointestinal ailments, tuberculosis, fungal infection, skin irritation, burns, bruises and scratches. Modaresi and Khodadadi (2014) administered@100 mg/kg and $200 \mathrm{mg} / \mathrm{kg}$ of Aloe vera to the rats for 20 days and they had reported that Aloe vera increased the number of stem cells and primary spermatocytes significantly as compared to control group. They also stated that Aloe vera increased stem cells and primary spermatocytes by preventing apoptosis of germinal cells, enhancing cell division and stimulating the leydig cells to increase testosterone production (Estakhr and Javdan 2011). The flavonoids are natural herbal phytoestrogens present in the Aloe vera having estrogen-like activity. Vitamins, present in Aloe vera improve testicular weight, seminiferous tubule diameter and thickness of the germinal epithelium (Estakhr and Javdan 2011).

\section{Asparagus racemosus (Shatavari)}

Shatavari (Figure 1, O) is a powerful male boost up. Shatavari having cooling properties which equilibrium the heating herbs used to recover sperm count, such as, garlic, onion, ashwagandha. Shatavari prevents reduction of sperm count and enhance the libido.

\section{Citrullus vulgaris}

Citrullus vulgaris (Fig. 1, E) or watermelon (seed extract) has copious antioxidants (lycopene, beta carotene) and several amino acids (arginine, citrulline) as reported by Kamil et al. (2011). Numerous studies have stated that antioxidants and vitamin A, B, C, and $\mathrm{E}$ in diet can protect sperm DNA against free radicals and augment blood-testis barrier stability (Jedlinska-Krakowska et al. 2006; Fathiazad et al. 2013). Khaki et al. (2013) reported that administration of $55 \mathrm{mg} / \mathrm{kg}$ Citrullus vulgaris extract for 28 successive days, significantly increased sperm concentrations, motility and viability in experimental group as compared to control.

\section{Cinnamomum zeylanicumon}

Cinnamomum belongs to the family Lauraceae species (Fig. 1, F) which contains volatile oils, tannins, terpenoids, mucilage, oxalates and starch. Phytochemical present in C. zeylanicumare have significant germicidal, antiulcerogenic and cytotoxic effects. Shah et al. (1998) reported that the extract of Cinnamomum increased the weight of testes, cauda epididymis and seminal vesicles also sperm count and motility in the treated male mice. Khaki (2015) stated that the administration of $75 \mathrm{mg} /$ $\mathrm{kg}$ of Cinnamomum for 28 days had significantly increased the sperm concentration, motility, viability and total testosterone concentration. Shalaby and Mouneir (2010) reported that the oral administration of C. zeylanicum extract @ $500 \mathrm{mg} / \mathrm{kg}$ to diabetic male rats for 65 days increased the weight of testes and seminal vesicles, improved semen quality and quantity, and increased serum insulin and testosterone levels and decreased the degenerative lesions seen in the testes of diabetic rats.

\section{Cardiospermum halicacabum}

Cardiospermum halicacabum (balloon vine) is a perennial herb (Fig. 1, G). It is found in the country of Sri Lanka. The roots of the plant are used against nervous disorders (Kapoor and Kumar, 2013). The leaves of the plant are used in abnormal suppression of menstrual cycle. The plant having the phytochemical of flavones, aglycones, triterpenoids, glycosides, and a variety of fatty acids and volatile ester (Annadurai et al. 2013). Peiris et al. (2015) reported that administration of aqueous leaf extract of Cardiospermum halicacabum increased the total sperm count and percentage of motile sperm. It is also used as a diaphoretic, diuretic, emetic, emmenagogue, laxative, refrigerant, stomachic, and sudorific (Menichini et al. 2014).

\section{Chlorophytum borivilianum}

Chlorophytum borivilianum (Safed Musli) having spermatogenic assets and it helps to enhance the 
sperm quality as well as the sperm count (Fig. 1, Q). It also increases the testosterone levels which further enhances blood circulation to the genitals for lengthier erections. It can be efficient in the treatment of male infertility and other sexual disorders like erectile dysfunction, prevent premature ejaculation as well as to improve the sperm count.

\section{Cynomoriumcoccineum}

Cynomoriumcoccineum Linn. (Cynomoraceae) is a parasitic plant with no leaves and no chlorophyll. This herb's aqueous extract has been proven to improve sperm count, percentage of viable sperm, and sperm motility, decrease the quantity of aberrant sperm, and increase spermatogenesis (Abd El-Rahman et al. 1999).

\section{Danae racemose}

Khaki et al. (2009) reported that administration of Danae racemose (Fig. 1, H) @ 200 mg/kg and 400 mg/ $\mathrm{kg}$ to the rats for 28 successive days significantly increased the sperm motility and viability. The Danae racemosa plant extract considerably reduced the Malondialdehyde (MDA) level and sperm abnormality in treated groups as compared to control.

\section{Eurycoma longifolia}

Eurycoma longifolia or Jack (Simaroubaceace), is a popular aphrodisiac herb in Malaysia (Cyranoski, 2005). In naive male rats, administration with $E$. longifolia extract resulted in successful induction of sexual drive (Chopra et al. 1958). By increasing the duration of coitus and copulation frequency, an ethanol extract of this herb boosted the sexual drive and performance of the treated male rats (Ang and Sim 1997).

\section{Mucuna pruriens}

This thick, oily plant has a sweet, yet occasionally bitter flavour. In the male albino rat, alkaloids produced from $M$. pruriens seeds were discovered to enhance spermatogenesis and overall weight of the testicles and accessory glands (Saksena and Dixit 1987). Increased mounting frequency, ejaculation latency, and intromission frequency indicate that M. pruriens can stimulate sexual activity in male rats (Amin et al. 1996; Suresh et al. 2010). M. pruriens was proven in a study to effectively recover spermatogenic loss caused by ethinyl estradiol treatment in male rats, and the herb's therapeutic effects were mediated by reduced ROS, apoptotic regulation, and an increase in the number of germ cells. M. pruriens' main ingredient, L-DOPA, is mostly responsible for its pro-spermatogenic characteristics (Singh et al. 2013). Sexual potency and behavior, libido, sperm parameters, and endocrine levels all improved significantly when $M$. pruriens seed extract was used (Suresh and Prakash 2012). Lipids, triglycerides, cholesterol, phospholipids vitamin $\mathrm{A}, \mathrm{C}$, and $\mathrm{E}$ levels have all been improved by $M$. pruriens and restored the levels of SOD, catalase, GSH, and ascorbic acid in seminal plasma after fructose nullified oxidative stress-induced lipid peroxidation in seminal vesicles (Ahmad et al. 2008; Shukla et al. 2010). The Mucuna pruriens increases testosterone, LH, dopamine, adrenaline, and noradrenaline levels whilst declining FSH and PRL levels in infertile men, according to neuroendocrine studies. Treatment with M. pruriens enhances steroidogenesis and semen quality in infertile men (Shukla et al. 2008).

\section{Nigella sativa}

Nigella sativa is known as black seed (Fig. 1, I), belongs to the family of Ranunculaceae. Nigella sativa seeds rich in nutritional compounds like carbohydrates (glucose, rhamnose, xylose, and arabinose), fats, vitamins, minerals and proteins including essential amino acids (El-Mahmoudy et al. 2002; Mohammad et al. 2009). The seed also contains unsaturated fatty acids (linoleic and oleic acid), carotene, calcium, iron, and potassium (Ghosheh et al. 1999; Mohammad et al. 2009). Nigella sativa has important role in correcting the CNS functions by the abilities of Thymoquinone TQ to reduce the stress of epilepsy in rats, acts as an anticonvulsant, muscle relaxant, analgesic agent and CNS depressant action (Filippo et al. 2002; Hosseinzadeh et al. 2005). The majority of the pharmacological actions are accredited to the existence of thymoquinone as a major compound (Gilani et al. (2004). Thymoquinone have antioxidant effects and it increasing the oxidant scavenger system as well as its potent anti-inflammatory mediators, prostaglandins and leukotrienes (Salem 2005). Al-Sa'aidi et al. (2005) found that alcoholic 
extract of Nigella sativa@ 0.5 and $1.5 \mathrm{~g} / \mathrm{kg}$ body weight significantly increased the body weight, reproductive capacity in males by increasing the thickness and diameters of seminiferous tubules, enhanced the spermatogenesis, increased sertoli and Leydig cells, testosterone and follicle stimulating hormones production.

\section{Ocimum basilicum}

Ocimum basilicum is belonging to the family Lamiaceae, found in Asia, which is used as a nutritious food and herbal medicine. This plant is used as an antispasmodic, aromatic, digestive, carminative, stomachic and tonic agent (Supawan et al. 2007). It has antioxidant effects which might be due to the presence of flavonoids, phenylpropanoids, and rosmarinic acid in the aerial parts of the plant (Bors et al. 1997; Peluso, 2006). Supawan et al. (2007) reported that Ocimum basilicum significantly increased sperm motility, viability and sperm count when it fed @ 1.5 and $3 \mathrm{~g} / \mathrm{kg}$ body weight of extract for 40 consecutive days. It has significantly decreased the level of malondialdehyde (MDA) in treated animals.

\section{Phaleria macrocarpa}

Phaleria macrocarpa found in Indonesia. Phaleria macrocarpa, usually used for the treatment of cancer, diabetes, hypercholesterolemia, hypertension, heart disease, allergy etc. (Winarto and Mahkota 2002). The fruits of the plant contain alkaloid, saponin, flavoid, and polyphenol which can enhance the testicular function of male mouse (Gauthaman et al. 2002; Zhang et al. 2006). Parhizkar et al. (2014) reported that Phaleria macrocarpa enhance the number of spermatogonia cells and thickness of seminiferous tubules as well as improved rat's fertility when it administered @ $240 \mathrm{mg} / \mathrm{kg}$ of aqueous extract for 7 weeks. Rosen and Ashton (1993) reported that the saponin content of plants increases aphrodisiac properties by stimulating the androgen production.

\section{Phoenix dactylifera $\mathrm{L}$.}

Phoenix dactylifera L. (Fig. 1, K) or Date Palm Pollen (DPP) has been used to support good health and improving male or female fertility in Middle East and Asian countries (Mehraban et al. 2014). Mehraban et al. (2014) reported that Phoenix dactylifera significantly increased the sperm count, sperm motility and estradiol concentration in experimental rats as compared to control group when administered @120 mg/kg and $240 \mathrm{mg} / \mathrm{kg}$ for 35 days. The phytochemical present in DPP is estrone, $\alpha$-amirin, triterpenoidal saponins, flavonoids, cholesterol, rutin carotenoids, oestronesgonad stimulating agents which improves the male fertility and elicit gonadotrophin activity, regulates the spermatogenic cycle and increases estrogen receptors (Drew and Myers 1997; Zhang et al. 2006).

\section{Phyllanthus emblica (Amla)}

Amal is one of the most vital fruits in Ayurveda (Fig. 1, P). The plant grows in a warm climate. The fruit is recognized as rich source of Vitamin C. It also contains polyphenols, minerals like iron and zinc and vitamins like Carotenes and Vitamin B complex. As because of rich in Vitamin $\mathrm{C}$ and polyphenols, amla is a immense resource of antioxidants. Research has revealed that it has a high amount of tannins, which combined with polyphenols and gives the fruit a unique free radical scavenging property. This will helps to reduce the damage caused by free radicals on the body. It also sustains the cholesterol levels in the body by inhibiting the oxidative properties of a chemical called as thiobarbituric acid (TBA) that induces LDL oxidation.

\section{Piper longum (Pippali)}

Pippali (Fig. 1, L) is a revitalizing herb that has a warming, reviving, and kapha-reducing action. When it combined with Ashwagandha, it improves blood flow to the reproductive tissues (Dass 2007; Chauhan et al. 2014). Pippali, according to Ayurveda, increases life energy and expels toxins through respiration. It also helps with digestion, absorption, assimilation, and breathing, as well as relieving arthritic pain. In complex recipes, the normal dosage of this plant is 1 to 3 parts, or 250 $\mathrm{mg}$ to 1.5 grams. In high pitta or inflammatory situations, pippali should be avoided (Dass 2007).

\section{Punica granatum}

Punica granatum (Pomegranate) fruit have 52\% of total fruit weight, which having $78 \%$ juice and $22 \%$ seeds (Fig. 1, M). The fresh juice of pomegranate is rich in vitamin $C$ and polyphenolic compounds 
such as anthocyanins, punicalagin, ellagic and gallic acid (Seeram et al. 2005). Pomegranate has been used as anticancer (Afaq et al. 2005), antiproliferative, apoptotic (Seeram et al. 2005), HIV-I entry inhibitory, topical microbicidal (Neurath et al. 2004), cardioprotective (Sumner et al. (2005), antihyperlipidemic (Fuhrman et al. 2005) and potent antioxidant agent. Turk et al. (2008) stated that administration of $0.25 \mathrm{~mL}$ PJ plus $0.75 \mathrm{~mL}$ distilled water (PJ-low), $0.50 \mathrm{~mL}$ PJ plus $0.50 \mathrm{~mL}$ distilled water (PJmiddle) and $1 \mathrm{~mL}$ PJ (PJ-high) to the experimental rats for 7 weeks, significantly increased the seminiferous tubule diameter and germinal cell layer thickness. They also said that due to its increased antioxidant capacity which can protect the spermatozoa against peroxidative damage and simultaneously it increased the spermatogenic cell density and sperm quality in healthy rats. For this reason, it has a positive relation between consumption of pomegranate and sperm parameters.

\section{Sida cordifolia (Bala)}

The word "Bala" referred as strength in Sanskrit, and as a rejuvenative tonic herb for vata and pitta, which is used to nourish and strengthen all bodily tissues, particularly the muscle, plasma, muscle, bone marrow, and reproductive tissue (Dutta and Sengupta 2018). It's sweet, heavy, and greasy, and when taken in excess, it raises kapha. It's also moderately cooling. Bala is a powerful anti-vata herb used in Ayurveda to treat both physical and mental ailments. It is an important Ayurvedic herb in the treatment of balakshaya, or chronic fatigue, and in the rejuvenation of total health when physical or mental strength is exhausted. It works as a tonic to boost male fertility, stimulate spermatogenesis, and restore sexual strength (Dass 2007; Chauhan et al. 2014). This plant can be consumed or used as rubbing oil on the penis in conjunction with Ashwagandha to increase its tone and avoid premature ejaculation. Its use in conjunction with herbs like gokshura, ashwagandha, vidarikandha, saw palmetto, and kapikacchu has been shown to improve prostate health. Bala is usually taken in doses of 2 to 6 grammes twice a day (Dass 2007).

\section{Serenoa repens (Saw palmetto)}

Saw palmetto herb traditionally used for boosting sexual health in male. It has also been documented for treating impotence and other physical disabilities associated with poor sexual health in male. It nourishes each facet of male reproductive structure. In addition, this is useful for prostate health, libido and testicular atrophy, balance hormone levels. Modifiable testosterone levels can help in several aspects of health, including body composition, sex drive, mood, and cognition.

\section{Turnera diffusa (Damiana)}

This herb (Fig. 1, S) is thought to have libidopromoting properties, which may be helpful for both male and female. It might help to bring back reproductive health and treat the premature ejaculation or impotence.

\section{Terminalia chebula (Shilikha/ Haritaki)}

Terminalia chebula tree (Fig. 1, R) is commonly known as Indian walnut or Indian hog plum in English. This tree belongs to the Combretaceae family. Terminalia chebula trees are deciduous in nature and mostly raise in tropical and subtropical regions of India, Nepal, China, Sri Lanka, Malaysia, and Vietnam. This tree is relatively tall; growing to a height of $30 \mathrm{~m}$ and has alternately given oval leaves growing on the branches. It's having dull whitishyellow flowers that have a strong pungent smell. The fruit of the plant is yellow to orangish-brown in color and are ovoid drupe-shaped with five distinct longitudinal ridges along its surface. The fruit of Terminalia chebula having several bioactive agents like chebulin, chebulagic, and corilagin and antioxidants like pyrogallol, ferulic, vanillic, phloroglucinol, and caeffic acid. It also has twelve fatty acids including linoleic acid, oleic acid and palmitic acid, glucose, quinines and tannins. It can be used as potent laxative, astringent, purgative, anti-bilious and antioxidant for the treatment of several health abnormalities. It is tremendously useful in promoting sexual health of both males and females. Being a natural aphrodisiac, it helps in dropping the stress and stimulates the hormones for increasing libido. It improves the male and female fertility, can be used to treats several reproductive issues and increases virility and stamina in male.

\section{Withania somnifera (Ashwagandha)}

In India, Withania somnifera known as ashwagandha 
(Fig. 1, A) means "the smell of a horse" in Sanskrit, because of its root has a strong stench similar to that of horse urine. Another legendary similarity of the sexual vigour it may offer to men with that of a horse led to its moniker. Induction of spermatogenesis, better blood supply to the reproductive tissues, and regulated endocrine activities are only a few of the many benefits for male reproductive problems. It treats spermatorrhea, nocturnal emission, premature ejaculation, and an enlarged prostate, among other things. In rats, Withania somnifera protects against swimming-induced endocrine dysfunctions of male reproductive and combats stress-induced male infertility (Misra et al., 2005). Due to increased interstitial cell stimulating hormone and testosterone-mimicking actions, as well as stimulation of nitric oxide synthase, the aqueous extract of this herb has been demonstrated to promote spermatogenesis (Iuvone et al. 2003). Ambiye et al. (2013) used concentrated root extract of Ashwagandha @ 225 mg/kg for 90 days which resulted significant improvement of semen parameters and regulated sexual hormone levels in oligospermic males. This herb appears to fight oxidative stress by lowering lipid peroxidation and protein carbonyl content, boosting sperm count and motility, and restoring antioxidant enzyme levels in the seminal plasma. When $5 \mathrm{~g}$ /day for 3 months of Withania somnifera root powder was given to a normozoospermic infertile male every day for three months, it exhibited a considerable reduction in stress, increased antioxidants, and increased semen
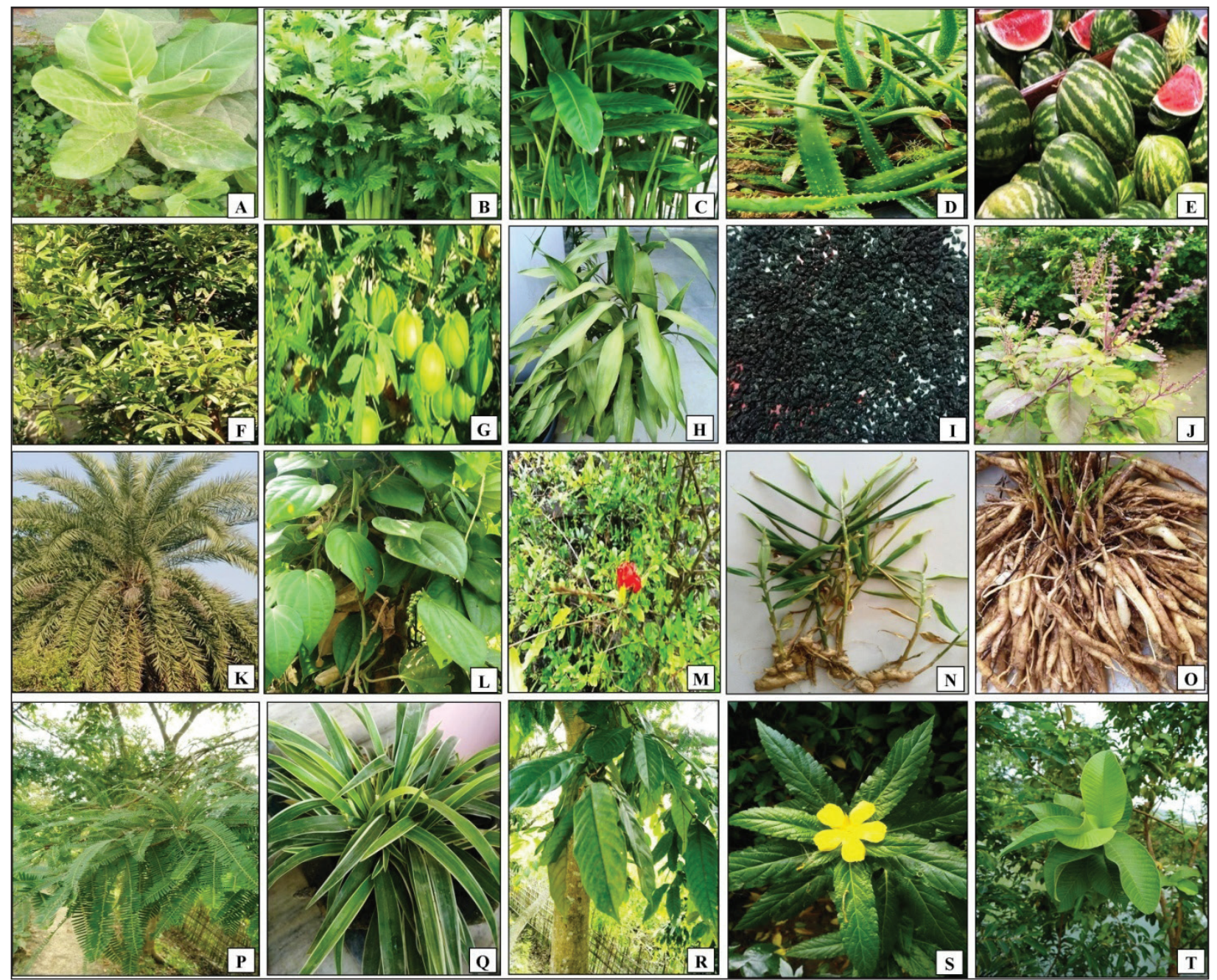

Fig. 1: Commonly used herbs for male fertility ((A) Withania somnifera; (B) Apium graveolens; (C) Alpinia galangal; (D) Aloe barbadensis miller; (E) Citrullus vulgaris; (F) Cinnamomum zeylanicumon; (G) Cardiospermum halicacabum; (H) Danae racemose; (I) Nigella sativa seed; (J) Ocimum sanctum; (K) Phoenix dactylifera. (L) L: Piper longum; (M) Punica granatum; (N) Zingiber Officinale; (O) Asparagus racemosus; (P) Phyllanthus emblica; (Q) Chlorophytum borivilianum; (R) Terminalia chebula; (S) Turnera diffusa; (T) Psidium guajava) 
volume and vitamin $\mathrm{A}, \mathrm{C}$, and E levels, as well as correcting fructose. Various studies have shown that this herb has an effect on the HPG axis, with one showing significant increases in blood testosterone and LH levels as well as lower levels of FSH and prolactin (PRL) in infertile men (Mahdi et al. 2009; Ahmad et al. 2010; Sengupta et al. 2018).

\section{Zingiber officinale}

Zingiber officinale (Ginger) plant (Fig. 1, N) belongs to family Zingiberaceae, which having about 1300 species in 50 genera, along with four other families is placed in the order Zingiberales (Garner-Wizard et al., 2006). Ginger is cultivated in Africa, China, India and Jamaica. The phytochemical agents of ginger classified to volatile oils (borneol, camphene, citral, eucalyptol, linalool, phenllandrene, zingiberine and zingiberolpenols (gingerol, zingerone and shogaol) and resin) which constitutes (1-3\%) mainly of zingeberene nonvolatile pungent compounds oleoresin constitutes (4-7.5\%) mainly gigerols and other constituents with more than $50 \%$ of starch (Fnimh, 2001; Ravindran and Babu, 2004). Ginger extract has anticancer, anti-oxidation, anti-inflammation and antimicrobial properties and a potent androgenic activity (Sharma et al. 1994; Kamtchouing et al. 2002). It is also used as a precursor of vitamin D3 (Kametani and Furuyama, 1987). Aleissa (2014) used $50 \mathrm{mg} / \mathrm{kg} / \mathrm{mouse}$ and $100 \mathrm{mg} / \mathrm{kg} / \mathrm{mouse}$ of ginger for 22 consecutive days and he found that it significantly increased the sperm motility and viability in both the groups. In another study of Aleissa et al. (2009) said that ginger extract significantly increased sperm functions i.e. sperm count, motility, viability and concentrations when it administered $50 \mathrm{mg} / \mathrm{kg}$ or $100 \mathrm{mg} / \mathrm{kg} /$ rat ginger for 20 days.

\section{Homemade preparations for improvement of male fertility}

Sarma (2020) reported that the pumpkin seeds have been used for treating infertility in males. The pumpkin seed should be boiled in water and then fed on regular basis. The raw garlic @ 4-5 cloves is helpful in treating male infertility and also improves the male reproductive function. The onion and roots of lady finger enhances male reproductive function and it is one of the most efficient and easiest treatments of male infertility. Grapes also help to increase the fertility of both male and female. It enhances quality and quantity of semen, sperm count and sperm motility. It also helps to reinforce the female reproductive system. This type of berries is recognized as "Vrishya", which means they help in erectile dysfunction and premature ejaculation. Clove (longg) is a wellliked Indian spice used in soups, stews, meats, sauces and biryani. Clove can increases male libido, prevent premature ejaculation and enhance sperm motility. Guava (Fig. 1, T) is a tropical fruit has the highest vitamin $C$ content. It has powerful antioxidant property and has been shown to significantly improve sperm motility, count, and morphology. Moringa oleifera seeds and leaves have high amount of sulfur-containing compounds known as glucosinolates which prevent the growth of prostate cancer cells. The seed and leaf extracts improves the penile blood flow. Moringa leaves and seeds have high content of antioxidants, which combat the oxidative damage that can hinder the sperm production process or damage sperm DNA. Studies in rabbits have shown that leaf powder of the plant considerably enhanced semen volume, as well as sperm count and motility.

\section{DISCUSSION}

Reduced vigor, libido, malfunction testicular tissues and leydig cells, failure of spermatogenesis counting azoospermia, asthenozoospermia, oligozoospermia, are the main causes of male infertility (Bener et al. 2009; Khojasteh et al. 2016). As per report of earlier worker, the chemotherapy, environmental pollution, toxic subtances, deficiency of minerals and vitamin have detrimental effects on normal spermatogenesis process (Baynes et al. 1999; Talukdar et al. 2016). Khojasteh et al. (2016) reported that feeding of antioxidants and vitamins A, B, C, and $\mathrm{E}$ can guard the sperm DNA from free radicals and augment the blood testis barrier steadiness. As from the present study, we have noticed that most of the plant extracts have foremost bioactive elements such as phenolic compounds (phenols, sterol, lignans and flavonoids), vitamins (B1, B2, B3, B6, C and E), folic acid, bio-trace elements (Ca, $\mathrm{Mg}, \mathrm{P}, \mathrm{Zn}, \mathrm{K}, \mathrm{Cu}$ and $\mathrm{Fe}$ ), various essential amino acids, volatile oils, polyphenols and saponins. These type of phytomedicines plays a positive role on spermatogenesis process and increases the 
sperm counts, sperm vitality, sperm concentration, increases Leydig cell counts, seminiferous tubule diameters, decreases anomalous spermatozoa and enhancing the sexual vigor, libido, erection, intromission and ejaculatory potency (Mohammadi et al. 2013; Talukdar et al. 2015; Khojasteh et al. 2016).

\section{CONCLUSION}

Herbal tonics replenish the quality and quantity of reproductive tissues by providing greater nutrition. Some herbs have both nourishing and stimulating characteristics. Due to the health risks, limited effectiveness, and high cost of modern male infertility treatments, herbal aphrodisiacs are regaining popularity and having a long-term impact on male reproductive health by improving sexual behavior, vigor, neuro-endocrine control, structural and functional aspects of reproductive tissues, and qualitative and quantitative improvements in semen as well as the shape and motility of sperm. Biomedical study should delve deeper to uncover additional secret mechanisms by which a plethora of herbs can help to eliminate male infertility, which is becoming a huge threat to future generations.

\section{REFERENCES}

Abarikwu, S.O., Pant, A.B. and Farombi, E.O. 2012. The protective effects of quercetin on the cytotoxicity of atrazine on rat Sertoli-germ cell coculture. Int. J. Androl., 4: 590-600.

Abd El-Rahman, H.A., El-Badry, A.A., Mahmoud, O.M. and Harraz, F.A. 1999. The effect of the aqueous extract of Cynomoriumcoccineum on the epididymal sperm pattern of the rat. Phytother. Res., 13: 248-250.

Achike, F.I. and Kwan, C.Y. 2003. Nitric oxide, human diseases and the herbal products that affect the nitric oxide signalling pathway. Clin. Exp. Pharmacol. Physiol., 30(9): 605-615.

Afaq, F., Saleem, M., Krueger, C.G., Reed, J.D. and Mukhtar, H. 2005. Anthocyanin- and hydrolyzable tannin-rich pomegranate fruit extract modulates MAPK and NF-kB pathways and inhibits skin tumorigenesis in CD-1 mice. Int. J. Cancer, 113: 423-33.

Ahmad, M.K., Mahdi, A.A., Shukla, K.K., Islam, N. and Rajender, S. 2010. Withania somnifera improves semen quality by regulating reproductive hormone levels and oxidative stress in seminal plasma of infertile males. Fertil. Steril., 94: 989-996.

Ahmad, M.K., Mahdi, A.A., Shukla, K.K., Islam, N. and Jaiswar, S.P. 2008. Effect of Mucuna pruriens on semen profile and biochemical parameters in seminal plasma of infertile men. Fertil. Steril., 90: 627-635.
Aleissa, M.S. 2014. Effect of Ginger supplements some reproductive parameters and spermatogenesis of mice. Indian J. Funda. App. Life Sci., 1: 271-277.

Aleissa, M.S., Mohammed Abd El Kader, S., Saad, H. and Ashraf, A.Q. 2009. Reproductive characteristics of The Arabian Sand Gazelles (Gazella subgutturosa marica). J. Saudi Society Agri. Sci., 1: 70-80.

Al-Sa'aidi, J.A.A., Al-Khuzai, A.L.D. and Al-Zobaydi, N.F. 2005. Effect of alcoholic extract of Nigella sativa on fertility in male rats. Iraqi J. Vet. Sci., 23: 123-128.

Ambiye, V.R., Langade, D., Dongre, S., Aptikar, P. and Kulkarni, M. 2013. Clinical Evaluation of the Spermatogenic Activity of the Root Extract of Ashwagandha (Withania somnifera) in Oligospermic Males: A Pilot Study. Evidence-based Complementary and Alternative Medicine, 57: 14-20.

Amin, Y.M.N., Rehman, Z.S. and Khan, N.A. 1996. Sexual function improving effect of $M$. pruriens in sexually normal male rats. Fitoterapial., 67: 53-58.

Anderson, K.E. 1993. Pharmacology of lower urinary tract smooth muscles and penile erectile tissues. Pharmacol. Rev., 45: 253-308.

Ang, H.H. and Sim, M.K. 1997. Eurycoma longifolia Jack enhances libido in sexually experienced male rats. Exp. Anim., 46: 287-290.

Annadurai, A., Elangovan, V., Velmurugan, S. and Ravikumar, R. 2013. Preliminary phytochemical screening and antibacterial of Cardiospermum halicacabum L. Adv. App. Sci. Res., 4: 302-308.

Argiolas, A. and Melis, M.R. 2013. Neuropeptides and central control of sexual behaviour from the past to the present: a review. Prog. Neurobiol., 108: 80-107.

Austin, D.F. 1991. Ipomoea littoralis (Convolvulaceae)taxonomy, distribution, and ethnobotany. Econ. Bot., 2: $16-25$.

Baynes, J.W and Thorpe, S.R. 1999. Role of oxidative stress in diabetic complications: a new perspective on an old paradigm. Diabetes, 48: 1-9.

Bener, A., Al-Ansari, A.A., Zirie, M. and Al-Hamaq, A.O. 2009. Is male fertility associated with type 2 diabetes mellitus? Int. Urol. Nephrol., 41: 777-784.

Bors, W., Michel, C. and Stettmaier, K. 1997. Antioxidant effects of flavonoids. Biofactors, 6: 399-402.

Chaudhuri, P., Bhattacharya, K. and Sengupta, P. 2014. Misty role of amygdala in female reproductive behavior. Int. J. Pharm. Pharm. Sci., 6: 563-564.

Chopra, R.N., Chopra, I.C., Handa, K.L. and Kapur, L.D. 1958. In: Chopra's Indigenous Drugs of India. $2^{\text {nd }}$ edition, UN Dhur and Sons Private Limited, Calcutta, India.

Cyranoski, D. 2005. Malaysian researchers bet big on homegrown Viagra. Nat. Med., 11: 912.

Dohle, G.R., Smit, M. and Weber, R.F. 2003. Androgens and male fertility. World J. Urol., 21: 341-345.

Drew, A. and Myers, S. 1997. Safety issues in herbal medicine: implications for the health professions. Med. J. Aust., 166: 538-541. 
Duduku, K., Rosalam, S. and Rajesh, N. 2011. A review of antioxidant potential of medicinal plant species. Food and Bioproducts Processing, 89: 217-233.

El-Mahmoudy, A., Matsuyama, H., Borgan, M.A., Shimizu, Y. and El-Sayed, M.G. 2002. Thymoquinone suppresses expression of inducible nitric oxide synthase in rat macrophages. Int. Immunopharmacology, 11: 1603-1611.

Estakhr, J. and Javdan, N. 2011. Spermatogenesis activity of Aloe vera in adult male rats. Pharmacology Online, 2: 886-889.

Farombi, E.O., Ekor, M., Adedara, I.A., Tonwe, K.E. and Ojujoh, T.O. 2012. Quercetin protects against testicular toxicity induced by chronic administration of therapeutic dose of quinine sulfate in rats. J. Basic Clin. Physiol. Pharmacol., 1: 39-44.

Fathiazad, F., Khak, A., Nouri, M. and Khaki, A.A. 2013. Effect of Cinnamon Zeylanicum on serum Testosterone and anti-oxidants levels in Rats. IJWHR., 1: 29-35.

Filippo, D., Antunio, L., Moretti, A. and Lovato, A.F.S. 2002. Seed Yield, Yield components, Oil content and essential oil content and composition of Nigella sativa L. and Nigella damascena L. Indust. Crops Prod., 15: 59-69.

Fnimh, A.C. 2001. Encyclopedia of Medicinal Plants, London, UK, pp. 155-156.

Fuhrman, B., Volkova, N. and Aviram, M. 2005. Pomegranate juice inhibits oxidized LDL uptake and cholesterol biosynthesis in macrophages. J. Nutr. Biochem., 16: 570-576.

Garner-Wizard, M., Milot, S.H.B., Neustadt, E.J., Oliff, H.S. and Oppel, M. 2006. Ginger, an herbal medicinal product with broad anti-inflammatory actions. J. Med. Food, 8: 125-132.

Gauthaman, K., Adaikan, P.G. and Prasad, R.N. 2002. Aphrodisiac properties of Tribulus Terrestris extract (Protodioscin) in normal and castrated rats. Life Sci., 71: 1385-1396.

Ghasemzadeh, A., Jaafar, E. and Rahmat, A. 2010. Antioxidant Activities, Total Phenolics and Flavonoids Content in Two Varieties of Malaysia Young Ginger (Zingiber officinale Roscoe). Molecules, 15: 4324-4333.

Ghosheh, O.A., Houdi, A.A. and Crooks, P.A. 1999. High performance liquid chromatographic analysis of the pharmacologically active quinones and related compounds in the oil of the black seed (Nigella sativa L.). J. Pharmaceutical Biomedical Analysis, 5: 757-762.

Gilani, A.U., Jabeen, Q. and Khan, M.A.U. 2004. A review of medicinal uses and pharmacological activities of Nigella sativa. Pakistan J. Biol. Sci., 4: 441-451.

Hamza, A.A. and Amin, A. 2007. Apium graveolens modulates sodium valproate-induced reproductive toxicity in rats. J. Exp. Zool. A Ecol. Genet. Physiol., 307: 199-206.

Hosseinzadeh, H., Parvardeh, S., Nassiri-Asl, M. and Mansouri, M. 2005. Intracerebroventricular administration of thymoquinone, the major constituent of Nigella sativa seeds, suppresses epileptic seizures in rats. Med. Sci. Monit., 11: BR 106-110.
Iuvone, T., Esposito, G., Capasso, F. and Izzo, A.A. 2003. Induction of nitric oxide synthase expression by Withania somnifera in macrophages. Life Sci., 72: 1617-1625.

Jedlinska-Krakowska, M., Bomba, G., Jakubowski, K., Rotkiewicz, T. and Jana, B. 2006. Impact of oxidative stress and supplementation with vitamins $\mathrm{E}$ and $\mathrm{C}$ on testes morphology in rats. J. Reprod. Dev., 52: 203-209.

Kametani, T. and Furuyama, H. 1987. Synthesis of vitamin D3 and related compounds. Med. Res. Rev., 7: 147-171.

Kamil, M.M., Gamal, M.F. and Shaheen, M.S. 2011. Fourier Transformer Infrared Spectroscopy for Quality Assurance of Tomato Products. J. Am. Sci., 7: 558-572.

Kamtchouing, P., Mbongue Fandio, G.Y., Dimo, T. and Jatsa, H.B. 2002. Evaluation of androgenic activity of Zingiber officinale and Pentadiplandra brazzeana in male rats. Asian J. Androl., 4: 299-301.

Kapoor, B.B.S. and Kumar, S. 2013. Ethnomedicinal plants of Barmer district, Rajasthan used in herbal and folk remedies. Indian J. Pharmaceutical Bio. Res., 1: 61-66.

Kaushik, D., Yadav, J., Kaushik, P., Sacher, D. and Rani, R. 2011. Current pharmacological and phytochemical studies of the plant Alpinia galanga. Zhong Xi Yi Jie He Xue Bao., 9: 1061-1065.

Khaki, A. 2015. Effect of Cinnamomum zeylanicumon on Spermatogenesis. Iran Red. Crescent Med. J., 17: e18668.

Khaki, A., Fathiazad, F., Ahmadi - Ashtiani, H.R., Rastgar, H. and Rezazadeh Sh. 2009. Effects of Danae racemosa on Spermatogenesis in Rat. J. Med. Plants, 31: 87-92.

Khaki, A., Fathiazad, F. and Nouri, M. 2013. Effects of Watermelon Seed Extract (Citrullus vulgaris) on Spermatogenesis in Rat. Int. J. Women's Health Reprod. Sci., 1: 99-104.

Khaki, A., Fathiazad, F., Nouri, M., Khaki, A.A., Ozanci Chelar, C. and Ghafari Novin, M. 2009. The effects of Ginger on spermatogenesis and sperm parameters of rat. Iran J. Reprod. Med., 7: 7-12.

Khare, C.P. 2007. Indian Medicinal Plants: An Illustrated Dictionary. Springer Science, New York, USA.

Khojasteh, S.M.B., Khameneh, R.J., Houresfsnd, M. and Yaldagard, E. 2016. A Review on Medicinal Plants Used for Improvement of Spermatogenesis. Biol. Med., (Aligarh) 8: 292.

Kooti, W., Ghasemiboroon, M., Asadi-Samani, M., Ahangarpoor, M. and Zamani, M. 2014. The Effect of Halcoholic Extract of Celery Leaves on the Delivery Rate (Fertilization and Stillbirths), the Number, Weight and Sex Ratio of Rat off Spring. Adv. Environ. Biol., 10: 824-30.

Kooti, W., Mansouri, E., Ghasemiboroon, M., Harizi, M. and Ashtary-Larky, D. 2014. The Effects of Hydroalcoholic Extract of Apium graveolens Leaf on the Number of Sexual Cells and Testicular Structure in Rat. Jundishapur J. Nat. Pharma. Prod., 4: e17532.

Madkour, N.K. 2014. Beneficial role of celery oil in lowering the di(2ethylhexyl) phthalate-induced testicular damage. Toxicol. Ind. Health, 30: 861-872. 
Mahdi, A.A., Shukla, K.K., Ahmad, M.K., Rajender, S. and Shankhwar, S.N. 2009. Withania somnifera improves semen quality in stress-related male fertility. Evid-Based Complement Alternat Med., 57: 6962.

Mayachiew, P. and Devahastin, S. 2008. Antimicrobial and antioxidant activities of Indian gooseberry and galangal extracts. LWT Food Sci. Technol., 41: 1153-1159.

Mazaheri, M., Shahdadi, V. and Nazari Boron, A. 2014. Molecullar and biochemical effect of alcohlic extract of Alpinia galanga on rat spermatogenesis process. Iranian J. Reprod. Med., 11: 765-70.

Mehraban, F., Jafari, M., Akbartabar Toori, M., Sadeghi, H. and Joodi, B. 2014. Effects of date palm pollen (Phoenix dactylifera L.) and Astragalus ovinus on sperm parameters and sex hormones in adult male rats. Iranian J. Reprod. Med., 10: 705-712.

Menichini, F., Losi, L., Bonesi, M., Pugliese, A. and Loizzo, M.R. 2014. Chemical profiling and in vitro biological effects of Cardiospermum halicacabum L. (Sapindaceae) aerial parts and seeds for applications in neurodegenerative disorders. J Enzyme Inhibition and Med. Chem., 29: 677-685.

Misra, D.S., Maiti, R.K., Bera, S., Das, K. and Ghosh, D, 2005. Protective effect of composite extract of Withania somnifera, Ocimum sanctum and Zingiber officinale on swimming induced reproductive Endocrine dysfunctions in male rat. Iranian J. Pharmacol. Therap., 4: 110-117.

Modaresi, M. and Khodadadi, A. 2014. The Effects of Aloe vera Extract on Spermatogenesis and Reproductive hormones in Mice. Res. J. Biol. Sci., 5: 165-168.

Mohammadi, F., Nikzad, H., Taherian, A., Amini Mahabadi, J.A. and Salehi, M. 2013. Effects of Herbal Medicine on Male Infertility. Anatomical Sci., 10: 3-16.

Mohammad, M.A., Mohamad, M.M.J. and Dradka, H. 2009. Effects of Black Seeds (Nigella sativa) on Spermatogenesis and Fertility of Male Albino Rats. Res. J. Med. Medical Sci., 2: 386-390.

Nehra, A., Colreavy, F., Khandheria, B.K. and Chandrasekaran, K. 2001. Sildenafil citrate, a selective phosphodiesterase type 5 inhibitor: urologic and cardiovascular implications. World J. Urol., 19: 40-45.

Neurath, A.R., Strick, N., Li, Y.Y. and Debnath, A.K. 2004. Punica granatum (pomegranate) juice provides an HIV-I entry inhibitor and candidate topical microbicide. BMC Infect. Dis., 4: 41.

Parhizkar, S., Zulkifli, S.B. and Dollah, M.A. 2014. Testicular morphology of male rats exposed to Phaleria macrocarpa (Mahkota dewa) aqueous extract. Iran J. Basic Med. Sci., 17: 384-390.

Peiris, L.D., Dhanushka, M.A. and Jayathilake, T.A. 2015. Evaluation of Aqueous Leaf Extract of Cardiospermum halicacabum (L.) on Fertility of Male Rats. Biomed. Res. Int., 2015: 175726.

Peluso, M.R. 2006. Flavonoids attenuate cardiovascular disease, inhibit phosphodiesterase, and modulate lipid homeostasis in adipose tissue and liver. Exp. Biol. Med. (Maywood), 231: 1287-1299.
Ravindran, P.N. and Babu, K.N. 2004. Ginger, the Genus Zingiber. CRC Press, Boca Raton.

Rosen, R.C. and Ashton, A.K. 1993. Prosexual drugs: empirical status of the "new aphrodisiacs". Arch. Sex. Behav., 22: 521-543.

Saksena, S. and Dixit, V.K. 1987. Role of total alkaloids of Mucuna pruriens Baker in spermatogenesis in Albino rats. Indian J. Nat. Prod., 3: 3-7.

Salem, M.L. 2005. Immunomodulatory and therapeutic properties of the Nigella sativa L. seed. Int. Immunopharmacol., 5: 1749-1770.

Sarma, C. 2020. Home remedies in ayurveda for male infertility. In: Male infertility. https:// www. drchanchalsharma. com/ ayurvedic-home-remedies-for-male-infertility

Seeram, N.P., Adams, L.S. and Henning, S.M. 2005. In vitro antiproliferative, apoptotic and antioxidant activities of punicalagin, ellagic acid and a total pomegranate tannin extract are enhanced in combination with other polyphenols as found in pomegranate juice. J. Nutr. Biochem., 16: 360-7.

Sengupta, P. 2014. Current trends of male reproductive health disorders and the changing semen quality. Int. J. Prev. Med., 5: 1-5.

Sengupta, P., Agarwal, A., Pogrebetskaya, M., Roychoudhury, S. and Durairajanayagam, D. 2018. Role of Withania somnifera (Ashwagandha) in the management of male infertility. Reprod. Biomed. Online, 36: 311-326.

Sengupta, P., Banerjee, R., Nath, S., Das, S. and Banerjee, S. 2015. Metals and female reproductive toxicity. Hum. Exp. Toxicol., 34: 679-697.

Shah, A., Al-Shareef, A.H., Ageel, A.M. and Qureshi, S. 1998. Toxicity studies in mice of common spices, Cinnamomum zeylanicum bark and Piper longum fruits. Plant Foods for Human Nutrition (Formerly Qualitas Plantarum) 3: 23-239.

Shalaby, M. and Mouneir, S.M. 2010. Effect of Zingiber officinale Roots and Cinnamon zeylanicum Bark on Fertility of Male Diabetic Rats. Global Vet., 6: 341-347.

Sharma, J.N., Srivastava, K.C. and Gan, E.K. 1994. Suppressive effects of eugenol and ginger oil on arthritic rats. Pharmacology, 49: 314-318.

Sharpe, R.M. 2010. Environmental/lifestyle effects on spermatogenesis. Philos. Trans. R. Soc. Lond. B. Biol. Sci., 365: 1697-1712.

Shukla, K.K., Mahdi, A.A., Ahmad, M.K., Jaiswar, S.P. and Shankwar, S.N. 2010. Mucunapruriens reduces stress and improves the quality of semen in infertile men. Evid-Based Complement Alternat. Med., 7: 137-144.

Shukla, K.K., Mahdi, A.A., Shankwar, S.N. and Ahmad, M.K. 2008. Effect of Mucunapruriens on hormonal status and semen quality in infertile males. Contraception, 78: 194.

Singh, A.P., Sarkar, S., Tripathi, M. and Rajender, S. 2013. Mucuna pruriens and its major constituent L-DOPA recover spermatogenic loss by combating ROS, loss of mitochondrial membrane potential and apoptosis. PLoS One, 8: e54655. 
Sumner, M.D., Elliott-Eller, M., Weidner, G., Daubenmier, J.J. and Chew, M.H. 2005. Effects of pomegranate juice consumption on myocardial perfusion in patients with coronary heart disease. Am. J. Cardiol., 96: 810-814.

Supawan, B., Chanida, P. and Nijsiri, R. 2007. Chemical compositions and antioxidative activities of essential oils from four ocimum species endemic to Thailand. J. Health Res., 3: 201-206.

Suresh, S. and Prakash, S. 2012. Effect of Mucuna pruriens (Linn.) on sexual behavior and sperm parameters in streptozotocin-induced diabetic male rat. J. Sexual Med., 9: 3066-3078.

Suresh, S., Prithiviraj, E. and Prakash, S. 2010. Effect of Mucuna pruriens on oxidative stress mediated damage in aged rat sperm. Int. J. Androl., 33: 22-32.

Talukdar, D.J., Shyam, J., Talukdar, P., Ahmed, K. and Gogoi, R. 2015. Documentation of traditional herbal medicines for reproductive disorders of livestock in Kamrup District of Assam. Int. J. Agri. Sci. Res., 5(6): 221-228.
Talukdar, D.J., Talukdar, P. and Ahmed, K. 2016. Minerals and its impact on fertility of livestock: A review. Agricul. Rev., 37(4): 333-337.

Toshimori, K., Ito, C., Maekawa, M., Toyama, Y. and SuzukiToyota, F. 2004. Impairment of spermatogenesis leading to infertility. Anat. Sci. Int., 79: 101-111.

Turk, G., Sonmez, M., Aydin, M., Yuce, A. and Gur, S. 2008. Effects of pomegranate juice consumption on sperm quality, spermatogenic cell density, antioxidant activity and testosterone level in male rats. Clin. Nutri., 27: 289-296.

Winarto, W.P. and Mahkota Dewa. 2002. The conservation and usage for medicinal treatment. Penebar Swadaya, Jakarta, Indonesia.

Zhang, Y., Xu, X. and Liu, H. 2006. Chemical constituents from Mahkota dewa. J. Asian Nat. Prod. Res., 8: 119-123.

Zhang, Y.B., Xu, X.J. and Liu, H.M. 2006. Chemical constituents from Mahkota dewa. J. Asian. Nat. Prod. Res., 8: 119-123. 